\title{
Microbial secondary succession in soil microcosms of a desert oasis in the Cuatro Cienegas Basin, Mexico.
}

Ecological succession is one of the most important concepts in ecology. However for microbial community succession, there is a lack of a solid theoretical framework regarding succession in microorganisms. This is in part due to microbial community complexity and plasticity but also because little is known about temporal patterns of microbial community shifts in different kinds of ecosystems, including arid soils. The Cuatro Cienegas Basin (CCB) in Coahuila, Mexico, is an arid zone with high diversity and endemisms that has recently been threatened by aquifer overexploitation. The gypsum-based soil system of the CCB is one of the most oligotrophic places in the world. We undertook a comparative 16S rRNA 454 pyrosequencing study to evaluate microbial community succession and recovery over a year after disturbance at two sites. Results were related to concurrent measurements of humidity, organic matter and total C and $\mathrm{N}$ content. While each site differed in both biogeochemistry and biodiversity, both present similar pattern of change at the beginning of the succession that diverged in later stages. After one year, experimentally disturbed soil was not similar to established and undisturbed adjacent soil communities indicating recovery and succession in disturbed soils is a long process. 
1 Nguyen E. López-Lozano ${ }^{1}$. Karla B. Heidelberg ${ }^{2}$, William C. Nelson ${ }^{2}$, Felipe 2 García-Oliva ${ }^{3}$, Luis E. Eguiarte ${ }^{1}$ and Valeria Souza ${ }^{1 *}$

$3{ }^{1}$ Departamento de Ecología Evolutiva, Instituto de Ecología, Universidad Nacional

4 Autónoma de México, Apartado Postal 70-275, 04510, México

$5 \quad{ }^{2}$ Department of Biology, University of Southern California, 3616 Trousdale Parkway, Los

6 Angeles, CA 90089-0371, USA

$7{ }^{3}$ Centro de Investigaciones en Ecosistemas, Universidad Nacional Autónoma de 8 México, A.P. 27-3 (Santa María de Guido) 58090, Morelia, Mich., México.

$9 \quad$ *corresponding author: Tel.: 1152 5556229006; Fax: 11525556228995

10 e-mail: souza@servidor.unam.mx 
Introduction

27 In ecological theory, succession is defined as the predictable manner by which

28 communities change over time during the colonization of a new environment or following

29 a disturbance (primary and secondary succession respectively) (Begon et al. 2006).

30 Bacterial succession has been explored in a variety of environments and over different

31 timescales (Fierer et al. 2010). However, there are many theoretical and methodological questions that remain unansweredsolved. For example the order of occurrence and species turnover inaccording to the successional stages can differ and be explained by stochastic or functional factors depending on the use of ecological or functional classifications instead of 16S rRNA taxonomic classifications (Burke et al. 2011a; Burke et al. 2011b). Notwithstanding, there are theoretical models for microbial community succession and assembly, most of them derived from those already well defined for macroorganisms (Prosser et al. 2007). Due to the complexity of the patterns observed in the succession of microbial communities, alternative explanations started to appear based on carbon (C) inputs to the systems, suggesting that species richness and the biomass of specific ecological groups change along successional stages (Fierer et al. 2010).

In recent years, the role of deterministic and stochastic processes in community assembly has been tested. It has been shown that bacterial community assemblages can be regulated by the local environment (species sorting) (Langenheder \& Székely 2011), massive immigration that can prevent competitive exclusion of species (mass effect) (Lindström \& Langenheder 2012), and neutral process, which assumes that all species are similar in their competitive ability and in dispersal. In the neutral process 
51 time. (Woodcock et al. 2007; Ofiteru et al. 2010). These mechanisms can co-occur,

52 resulting in microbial communities being structured by more than one process

53 (Langenheder \& Székely 2011). However, t-The development of such theoretical models

54 are based mostly on work done in laboratory environments, and little is known of what

55 happens in natural systems such as soils (Caruso et al. 2011; Navarro et al. 2009;

56 Nemergut et al. 2007; Schmidt et al. 2007). Data on how microbial communities change

57 through time in natural environments are needed in order to refine these theoretical 58 models.

60 Soils are among the most diverse microbial environments analyzed to date (Youssef \&

61 Elshahed 2009; Daniel 2005), which makes the identification of differences in community 62 diversity patterns between stable and disturbed soils challenging. Arid soils are thought

63 to have lower productivity and diversity than other soil habitats, and therefore may 64 provide a better opportunity to validate molecular ecosystems approaches to examine 65 the genetic and functional organization of native microbial consortia. Earth's arid regions 66 represent today nearly one third of total continental ecosystems (Collins et al. 2008) and 67 are thought to be more vulnerable under most scenarios of global climate change 68 (Intergovernmental Panel on Climate Change, 2007 report).

70 The Cuatro Cienegas Basin (CCB) in Coahuila, Mexico, is an arid zone that has recently 71 been threatened by aquifer overexploitation. The gypsum-based soil system at CCB is 72 one of the most oligotrophic environments in the world despite the high diversity in comparison with others arid soils (López-Lozano et al. 2012). Nevertheless, due to 74 recent and ongoing overexploitation of the deep aquifer in this oasis, we decided to 75 evaluate the community sensitivity after disturbance. In this study we experimentally 
76

77

78

79

80

81

82

83

84

85

86

87

88

89

90

91

92

93

94

95

96

97

98

99

100

sampled and disturbed soil microcosms with gama rays and sterilization. Samples were restored to their original site in a mesh bag that allowed migration._Then,- $\underline{c}$ Community composition as well as nutrient dynamics were followed and compared to neighboring undisturbed soil samples. The objective of this study was to evaluate the recovery of microbial biodiversity and biogeochemical characteristics of the Churince within the CCB during a process of microbial secondary succession over one year period after disturbance_- $\underline{a}$ And to find out if microbial successionthe shift pattern behaves like any of the previously proposed models. Our approach was designed to be experimentally analogous to sections of a forest cleared by removing the biota of an area, and tracking recolonization by migration.

\section{Materials and Methods}

Site description and experimental design. The sampling sites are located at the Churince oasis system on the west side of the Cuatro Cienegas Basin (CCB) at $740 \mathrm{~m}$ above sea level. This valley has $<15.0 \mathrm{~cm}$ of annual precipitation falling mainly during the summer. The dominant soil is gypsisol, and the predominant vegetation types are halophile and gypshophile grasses. As described before (López-Lozano et al. 2012), the Churince system consists of a spring, an intermediate lagoon, and a desiccation lagoon (Dry Lagoon), connected by short shallow creeks. Two sites separated by one kilometer were

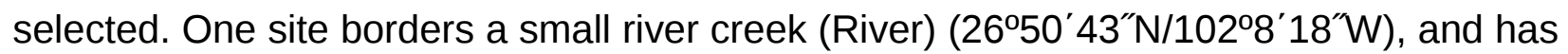
$60 \%$ of plant coverage. The grass Sporobolus airoides is the dominant plant. The other

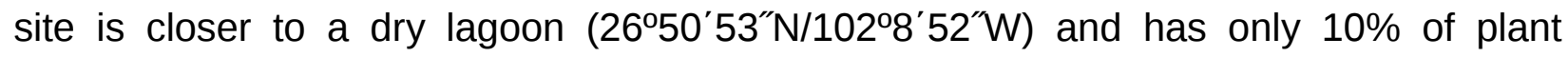
coverage. At this site the gypshophile grass, Sesuvium erectum, is the dominant plant species. The sites have alkaline soils with slight variation in the $\mathrm{pH}$ of 8.5-8.8. 
102 In January of $2007,20 \mathrm{~kg}$ of soil were collected from each site. The soil was mixed and

103 used to construct microcosms of $1 \mathrm{~kg}$ of soil in permeable bags of nylon mesh $(25 \times 25$

$104 \mathrm{~cm}$ ). The microcosms were sterilized by autoclaving followed by a dose of $25 \mathrm{kGy}$ of

105 gamma rays (at the Instituto Nacional de Investigaciones Nucleares, La Marquesa,

106 México). One microcosm sample from each site was immediately used for DNA

107 extraction as a control.

108

109 In February 2007, plots of $8 \times 8 \mathrm{~m}$ were established at each site. The plots were divided

110 in 64 quadrants of $1 \mathrm{~m}^{2}$, and 40 microcosm bags were placed randomly within the plots

111 as replicates. Every three months, three microcosm bags were collected randomly

112 during a period of one year (3, 6, 9 and 12 months), 12 in total for each site. The

113 remaining microcosms were deposited in the site in order to guarantee enough samples

114 in each sampling period but not analyzed for this experiment. In addition, three samples

115 from $15 \mathrm{~cm}^{3}$ of undisturbed soil next to the microcosms in each plot were randomly

116 collected at the beginning and end (12 months) of the experiment to describe the

117 community that potentially could colonize the microcosms. $50 \mathrm{~g}$ of each sample were

118 stored in liquid nitrogen until DNA extraction. The remaining soil was stored in black

119 plastic bags at $4^{\circ} \mathrm{C}$ during one month until processing in the laboratory for

120 biogeochemical analysis.

121

122 Soil biogeochemical analyses. Separate samples were oven-dried at $75^{\circ} \mathrm{C}$ to constant

123 weight for soil moisture determination by the gravimetric method (Reynolds 1970).

124 Measurements ofAll-carbon (C) forms were determined with a Total Carbon Analyzer

125 (UIC Mod. CM5012), while nitrogen (N) and phosphorus (P) forms were determined 
126 using a Bran-Luebbe Auto Analyzer III (Norderstedt, Germany). Total and inorganic C

127 were determined by dry combustion and coulometric detection (Huffman 1977). Organic

128 C was calculated as the difference between total and inorganic $\mathrm{C}, \mathrm{N}$ and $\mathrm{P}$

129 concentrations were determined following acid digestion; $\mathrm{N}$ was determined using a 130 modified Kjeldahl method (Bremmer \& Mulvaney 1982), and P was determined with the

131 molybdate colorimetric method following ascorbic acid reduction (Murphy \& Riley, 1962).

132 Microbial $\mathrm{C}$ (micC) and microbial $\mathrm{N}(\mathrm{micN})$ concentrations were determined from

133 field-moist samples by a chloroform fumigation extraction method (Vance et al. 1987).

134 Inorganic N (NH4+ and NO3-) was extracted from fresh sub-samples with $2 \mathrm{M} \mathrm{KCl}$.

135 followed by filtration through a Whatman No. 1 paper filter (Robertson et al. 1999), and determined colorimetrically by the phenol-hypochlorite method. Dissolved organic C, N and $\mathrm{P}$ were extracted in two grams of fresh material with deionized water after shaking for $1 \mathrm{~h}$, and filtering through a Whatman\# 42 filter and a $0.45 \mu \mathrm{m}$ nitrocellulose membrane (Jones y Willett, 2006). Dissolved organic C (DOC) was determined by combustion and coulometric detection (Huffman 1977). Dissolved organic N (DON) and dissolved organic P (DOP) were determined after acid digestion. DON was calculated as the difference between digested soluble $\mathrm{N}$ and $\mathrm{NH} 4+$ in deionized water extracts. The DOP was calculated as the difference between digested dissolved P and inorganic P (as

144 orthophosphate).

147 Statistical analyses. To evaluate significant differences in biogeochemical soil 148 parameters between sites and through the time during the microcosms experiment, we 149 analyzed biogeochemical variables with a repeated measures analysis of variance 
150 (RMANOVA) with one between-subject factor (site: Dry Lagoon and River) and one

151 within factor (sampling date: 3, 6, 9 and 12 months). In order to compare

152 biogeochemical soil parameters between sites, and between disturbed and undisturbed

153 soil in the last sampling date (12 months), we carried out a two-way analysis of variance

154 (ANOVA) (factor 1 levels: sites Dry Lagoon and River; factor 2 levels: undisturbed soil

155 and microcosm).

156

157 The relationship between microbial community composition in terms of the most 158 abundant bacterial families, soil characteristics and samples (date and site) was 159 analyzed by canonical correspondence analysis (CCA). In this analysis, tfhe samples

160 are represented by a centroid. Its position is indicative of the relationship between a 161 specific sample and either of the ordination axes. Soil characteristics are represented by vectors. Vectors of greater magnitude and forming smaller angles with an ordination axis

163 are more strongly correlated with that ordination axis. High scores of absolute value for a given family or a given site on a CCA axis indicate that it is highly related to the axis and to the environmental variable exhibiting high correlation to the axis. All soil

166 characteristics were tested for significant contribution to the explanation of the variation in bacterial family community composition with an ANOVA like permutation test to 168 assess the significance of constraints. Only variables that were significant by the permutation test at the $P \leq 0.05$ level were included in the CCA biplot. The CCA was performed using the package Vegan in $\mathrm{R}$ (http://www.r-project.org/). In the

171 supplementary material, we added a DCA analysis without the restrictive variables for 172 comparison (figure S2). 
175 (EPICENTRE Biotechnology) according to the manufacturer's instructions, with an

176 additional step of bacterial isolation using the fractionation centrifugation technique

177 described in (Holben et al. 1988). This step was performed on frozen $50 \mathrm{~g}$ soil samples

178 before DNA extraction as a way of reducing the remaining concentrations of salts,

179 polysaccharides and secondary compounds. DNA was stored at $-20^{\circ} \mathrm{C}$.

180

181 In order to confirm sterilization in the control microcosms, the DNA region coding for $16 \mathrm{~S}$

182 rRNA was PCR amplified using universal primers (Tables S1 and S2). Since no band 183 was recovered in a PCR gel run using the sterilized soil, the sterilization was assumed to 184 be effective.

186 Pyrosequencing of 16S rRNA tags. 16S rRNA genes were amplified from each sampling 187 date (pooled DNA from the three subsamples was used as template) using the 939F 188 (TTGACGGGGGCCCGCAC) and 1492R (TACCTTGTTACGACTT) paired primers. 189 Sequencing was undertaken using the standard Roche 454 Titanium LIB-A kit with 190 multiplex identifier sequence (MID) tags (Table S3) (Sun et al. 2011) at the Research 191 and Testing Laboratory (Lubbock, TX).

192

193 Bioinformatic analysis of barcoded 16S ribosomal RNA gene libraries: Mothur 194 open-source software package ( $v$ 1.15.0) (Schloss et al. 2009) was used for processing, 195 clustering, and classification of the quality screened sequence data. Raw sequences 196 were screened for potential chimeric reads using Chimera.slayer (Haas et al. 2011) and 197 the linked SILVA template database (26\%). Sequences containing homopolymer runs of 1989 or more bases, those with more than one mismatch to the sequencing primer and 199 those longer than 565 bp were eliminated. Group membership was determined prior to 
200 trimming of the bar-code MID and primer sequence. Sequences were aligned against 201 the manually curated bacterial SILVA 16S rRNA gene template using the nearest 202 alignment space termination (NAST) algorithm (Schloss 2010; DeSantis et al. 2006), 203 and manually trimmed for the optimal alignment region (start $=28596$, end $=38347$ ), 204 which yielded aligned fragments of $270 \mathrm{bp}$ long, including both the V6 and V7 regions. 205 Pre-clustering, based on the SLP clustering algorithm (Huse et al. 2010), was used to 206 reduce the effect of pyrosequencing errors on subsequent analysis. A pairwise distance 207 matrix was calculate across the non-redundant sequence set, and reads were clustered 208 into operational taxonomic units (OTUs) at 3\% distance using the furthest neighbor 209 method (Schloss \& Handelsman 2006). This matrix was used to calculate the similarity 210 based on the Bray-Curtis and Jaccard Index between the samples in each site and to 211 create a cluster diagram of sample similarity. The sequences and OTUs were categorized taxonomically using Mothur's Bayesian classifier and the SILVA bacterial reference set. A single-representative sequence from the center of -each OTU grouping was classified using a naïve Bayesian approach (Wang et al. 2007). The taxonomic reference database was composed of unique, full-length sequences from the SILVA SSU 216 Ref v.106 database (http://www.mothur.org/wiki/Silva_reference_files) (Pruesse et al. 217 2007). To account for the effects of different sequencing depths on the alpha-diversity 218 measurements, the sample sets were normalized to equal abundance of the sample 219 with the least sequencing effort (Dry Lagoon, 9 months; 10,441 sequences; Table S3). 220 Alpha-diversity statistics including Chao1 non-parametric species richness estimate 221 (calculates the estimated true species diversity of a sample based in the number of 222 singletons and doubletons), Shannon indices, Shannon-based richness estimate 223 (diversity indices as a quantitative measure that reflects how many different OTUs there 224 are in the dataset, simultaneously takes into account how evenly the OTUs are 
225 distributed), and Good's coverage estimate (what percent of the total OTUs is 226 represented in the sample), were generated for each sample using the same program.

228 The GenBank accession numbers for 16S rRNA pyrosequences in this work are in the 229 BioProject: PRJNA167137. The samples identificationstD for microcosms in the Dry 230 Lagoon are: before sterilization SRS346170, at 3 months SRS346171, at 6 months 231 SRS346172, at 9 months SRS346173 and at 12 months SRS346174. The samples ID 232 for microcosms in the River are: before sterilization SRS346176, at 3 months SRS346177, at 6 months SRS346178, at 9 months SRS346179 and at 12 months SRS346180. The samples ID for the undisturbed adjacent soil without disturb-at 12 months are SRS346175 for the Dry Lagoon, and SRS346181 for the River.

\section{Results}

Nutrient fluctuations during the secondary succession. In order to understand the relationships between the changes in community composition and nutrient transformations that occurred during the secondary succession process in the Churince soils, the soil samples were biogeochemically characterized and compared. We found that the CCB soil at the Dry Lagoon site was more oligotrophic (C:N:P ratio of 125:5:1)

243 than the River site (C:N:P ratio 300:16:1) and in comparison with a general "average" 244 soil C:N:P of 186:13:1 (Cleveland \& Liptzin 2007). RMANOVA analysis revealed consistent differences in the soil nutrients between sites across time (Table 1). The Total

246 Organic C was higher at the site adjacent to the River throughout the sampling, even 247 though it showed a fluctuating pattern during the secondary succession experiment, 248 probably due to both seasonal effects and succession stages (Table 1). The same 249 pattern was observed for Total $\mathrm{N}$ and Total P. On the other hand, microbial C (micC) as 
250 an indicator of microbial biomass showed similar fluctuations in both sites (Table 1).

251 Values increased during the first three and six months after sterilization, then micC

252 decreased at 9 months and increased again in the last sampling date. Ammonium

253 showed contrasting patterns between sites. At the Dry Lagoon, ammonium increased 254 showing higher values at 6 months, and then decreased gradually. At the River, 255 ammonium increased gradually to drop in the last sampling. The microbial $N$ (micN) 256 increased in samples near the River, but presented fluctuations in the Dry Lagoon. Only 257 the nitrate was higher in the Dry Lagoon microcosms but there were not significant 258 differences by time. ANOVA analysis of soil nutrients in microcosms samples and 259 undisturbed adjacent soil at 12 months showed significant differences between 260 treatments in Total Organic C, dissolved organic N (DON), dissolved organic P (DOP) 261 and ammonium (Table 2). However, undisturbed soil samples were similar to the 262 perturbed samples in their total $\mathrm{N}$ and $\mathrm{P}$ content (TN, TP and DIP) (Table 2). These data 263 suggests that, in general, the sampling sites are different and as such, respond 264 differently to perturbation.

266 Evaluation of community structure by $16 S$ rRNA amplicons. The number of high quality 267 sequences per library ranged from 10,441 to 41,074 per sample (Suppl. Table S3). Once 268 the dataset was normalized to the sample with the lowest sequencing effort, 79,303 269 OTUs at $97 \%$ similarityitude were identified. The majority of sequences (> 80\%) 270 belonged to one of the nine major phyla (arranged in order of abundance):

271 Acidobacteria, Proteobacteria, Bacteroidetes, Firmicutes, Chloroflexi,

272 Deinococcus-Thermus, Gemmatimonadetes, Actinobacteria, or Candidatus division TM6 273 (Table 3, figure S1). A higher number of unclassified sequences were observed at the 274 Dry Lagoon site than in the River site. Interestingly, none of the sequences belonged to 
275 any eukaryotic specie which mitochondria and chloroplast would be amplified by these 276 techniques. Suggesting that while wind and water could help the colonization processes; 277 nematodes and other invertebrates did not play an important role in the migration of 278 bacteria between disturbed and undisturbed sites.

279

280 Despite the differences observed in nutrient content between sites, the 16S rRNA 281 sequence analysis showed similar variations in the diversity and community composition 282 of the sites, even though the overall diversity was higher in the River during the entire sampling period (Table 4, Figure 1). At both sites, during the first six months (3 and 6 months samples) there was an increase in diversity, then the diversity decreased by nine months and increased again after one year (12 months) following a similar fluctuating pattern to the biomass. Contrasting the diversity in the last sampling date with the diversity of the adjacent undisturbed soil, we observed that the undisturbed soil had higher diversity than microcosms samples (Table 4).

Prior to disturbance, both Dry Lagoon and River communities were dominated by Acidobacteria (44\% and 60\%, respectively) (Table 3). The Dry Lagoon had a large proportion of bacteria that were unclassified at the $97 \%$ identity threshold (around-12 to $33-\%$-of the sequences). Proteobacteria were also abundant, comprising $9 \%$ of the Dry Lagoon sequences and $35 \%$ of the River sequences. Overall there was a gradual increase in the abundance of the Bacteroidetes during the succession process, which were not abundant in the first sampling (less than 0.24\%) but increased with time

297 (around 7-9\%). Autotrophic phyla such as Clorobi, Chloroflexi and Cyanobacteria, 298 increased in abundances the first nine months and then decrease their abundance in the 299 last sampling (12 months) (Table 3). 
301 A more detailed analysis at the family level showed that the families present before the 302 sterilization in low abundance were not found after 3 months, but many of them were 303 recovered by 6 months and onward (Table S4). The initial colonizers at 3 months were 304 different between sites, but in both cases, the majority of the identified families were 305 related to known opportunistic heterotrophs. In the Dry Lagoon the most abundant 306 families were Moracellacea, Streptococcaceae, Alcaligenaceae, Pseudomonadaceae, 307 Micrococcaceae and Bacillaceae. At the River site at 3 months, Holophagaceae, 308 Acidobacteriaceae, GIF3 (Chloroflexi), Enterobacteriaceae, Streptococcaceae, 309 Listeriaceae and Bacillaceae were found. By 6 months the abundance of unclassified 310 taxa increased, but also the abundance of families that include previously described 311 members with other metabolic capabilities besides heterotrophy (Table S4). The relative 312 abundances of some bacterial groups at different taxonomic levels correlated 313 significantly with Total Organic $\mathrm{C}$, Total $\mathrm{N}$, humidity and $\mathrm{NO}_{3}^{-}$(Table 5), and these trends 314 were corroborated with the CCA (Figure 2).

316 Similarity between sites and samples through the time, measured with the Bray-Curtis 317 distance and Jaccard coefficient using OTUs at $97 \%$ of identity, achieved a peak three 318 months after sterilization, while it was lower before sterilization and six, and nine months 319 after sterilization. After a year the microcosms communities were more similar to the 320 communities from undisturbed soil at each site (Figure 3).

\section{Discussion}

324 Microbial diversity and secondary succession in a gypsum based soil. In this study we 
325 analyzed the bacterial secondary succession of experimentally disturbed soil

326 microcosms at two sites over one year. While each site differed in both biogeochemistry

327 and biodiversity, both present similar community composition at the beginning of the

328 experiment. However, successional patterns differed in later stages. This suggests an

329 species sorting effect at the beginning of the experiment, followed by a more neutral

330 process in later stages. At the end of the experiment, comparing the adjacent soil

331 samples with the experimentally disturbed soil, the microbial communities at either site

332 do not resemble adjacent undisturbed microbial communities. Both disturbed soils were

333 most closely related to each other (Figure 3).

334

335 Four factors contribute strongly to differences in our sites: humidity, Total N, Total

336 Organic $\mathrm{C}$ and Total P. IAlso the first three factors were identified as the most correlated

337 variables with the relative abundance of the bacterial groups. These factors have been

338 considered as part of the best group of soil variables for predicting microbial community

339 composition in arid lands (Collins et al. 2008; Wall \& Virginia 1999). We also found that

340 Total $\mathrm{P}$ in the soil explained some variability. This was expected, as $\mathrm{P}$ is the most limiting

341 nutrient in CCB (Elser et al. 2005).

343 In a previous 16S rRNA Sanger-based clone library analysis (López-Lozano et al., 344 2012), 15 phyla and 40 classes were identified from 293 sequences in the harsher Dry 345 Lagoon. The River site had 16 phyla and 36 classes identified from 223 sequences. 346 Even with the higher sequencing effort afforded by 454 pyrosequencing, we still only 347 captured $52 \%$ to $81 \%$ of the microbial communities in our samples (Figure 1 and Table 348 4). This was surprising, since in more fertile and wet soils analyzed with similar 349 sequencing effort, the maximum number of OTUs at $97 \%$ of identity seldom exceeds 
$\sim 5,600$ OTUs (Roesch et al. 2007), while in our more diverse sample, we estimated

3519,000 OTUs at $97 \%$ identity. However, the sites analyzed in this study differed in

352 diversity, with soil adjacent to the River being more diverse than the Dry Lagoon if we

353 compare the OTUs at $97 \%$ (Table 4). In the previous clone library study the same

354 pattern was observed (López-Lozano et al. 2012). We also evaluated the community

355 composition in terms of "ecological groups", considering groups in which abundance

356 correlated with high or low C mineralization rates (copiotrophs or oligotrophs,

357 respectively) in general soil surveys (Fierer et al. 2007, 2010), and widely known

358 autotrophs (phototrophs such as Cyanobacteria and Chloroflexi). Also we determined

359 some metabolic capabilities by comparison of the sequences with the closer cultivated

360 organisms. Despite the broad ecological classification based only in 16S rRNA gene

361 sequences, our results showed interesting trends in groups considered as oligotrophs,

362 copiotrophs (organism that need more nutrients) as well as heterotrophs and autotrophs.

364 The 16S rRNA libraries of both sites are dominated by Acidobacteria in all samples. This 365 is one of the most common phyla found in soil libraries worldwide (Janssen 2006). The 366 Acidobacteria are in general oligotrophic (Eichorst et al. 2007; Fierer et al. 2007) and 367 have been shown to comprise 50\% of clone libraries in arid soils (Dunbar et al. 1999;

368 Kuske et al. 1997), but they are less abundant in more nutrient-rich agricultural soils 369 (Nagy et al. 2005; Roesch et al. 2007). Hence, it is not surprising that they represent $370-30-60 \%$ of bacteria in all our libraries in CCB sampling sites. In contrast, Bacteroidetes 371 have been classified as copiotrophs in general (Fierer et al. 2007). In our libraries

372 Bacteroidetes become much more abundant at the 6 months sampling, and it is possible

373 that these phyla appear when the accumulation of organic material is enough to sustain 374 the mineralization rate of this group. In fact, between 6 and 9 months there was a drop 
375 in the Dissolved Organic $C$ while the microbial $C$ increase in the soil microcosms.

376 Autotrophic groups, such as Cyanobacteria are abundant at both sites. This phylum is 377 common in most environments including soil and biological soil crust of arid zones 378 (Gundlapally \& Garcia-Pichel 2006; Nagy et al. 2005). The abundance of yet another 379 autotrophic group, the Chloroflexi, increased during the initial stages of succession (3-9 380 months) but decreased in the last sampling date (12 months). With the exception of high 381 Chloroflexi in the River sample during the first samplings, the majority of the colonizers 382 are opportunistic heterotrophs (a greater part members of Firmicuttes, 383 Betaproteobacteria and Gammaproteobacteria). It is possible that especially in the Dry 384 Lagoon site, the initial colonizers were benefited by the Dissolved Organic C, released 385 finding of preferential growth of opportunistic heterotrophs during early succession agrees with the findings from another study using outdoor sterile microcosms seeded by 389 rainwater bacteria (Langenheder \& Székely 2011). These authors found that neutral and species sorting processes interacted during the assembly of bacterial communities, and 391 the importance of each depended on how many generalists and specialists were present 392 in the community. We suggest that in our microcosms, the initial faster growing community (generalists) depleted the nutrients, and then were out competed by groups 394 that have alternative energy sources (specialists). At 6 months the abundance of groups 395 with more specialized metabolic capabilities increased, and the taxa with low 396 abundances before the sterilization, "the rare biota" that were not present after three 397 months returned to the community from this sampling date. The observed nitrate 398 accumulation in the Dry Lagoon site could be due to an increase in nitrification, an 399 alternative mechanism of obtaining energy that could persist under those conditions 
400 (Montaño et al. 2007). Also, the higher DOP in the Dry Lagoon site suggests that $P$ 401 mineralization is not occurring as efficiently as in the River site, perhaps because of 402 limited energy for exo-enzyme production necessary for acquisition (F. Garcia-Oliva, 403 personal communication). Hence, the Dry Lagoon site might be supporting a more 404 oligotrophic microbiota than the River site. Conversely, changes in DOC at the River site 405 correlated with changes in microbial C. Additionally, ammonium correlated with microbial $406 \mathrm{~N}$, suggesting that the initial surge of nutrients could have facilitated a faster migration of 407 the neighboring heterotrophic biomass in this site than in the Dry Lagoon site. 408 Photosynthetic autotrophs (such as Chloroflexi) seem to be sufficient for nurturing the 409 community in the River site providing C sources, since nitrates and DOP are scarce, 410 indicating low nitrification rates.

412 Regarding the diversity shifts, both sites showed similar patterns. There is an initial 413 increase in the Shannon index, followed by a decrease at 9 months and an increase at 41412 months. We do not discard the possibility that these convergent patterns only in the 415 417 (Table S5).

The Bray-Curtis similarity index and Jaccard similarity coefficient analyses, suggest that 420 even though the initial communities are similar in composition, they differ in later stages. 421 In addition, the analysis by phylogenetic and ecological groups, suggest that the 422 communities respond in a similar trajectory of initial colonization first by heterotropic 423 generalists and later specialists. However the River site was characterized by higher 424 nutrients and diversity, together with the continuous presence of Cloroflexi in high 
425 abundance suggest an early food web based on primary production. This pattern is 426 similar to the early stages of the autotrophic succession suggested by Fierer et al. 427 (2010). Our experimental design cannot be used to test this autotrophic model, but our data show that the colonizers were a mix of heterotrophs and autotrophs.

430 In this study we found community composition of the soil microcosms after perturbation 431 did not recover to similar communities found in the undisturbed soil community after one 432 year. We are not assuming that there is only one "climax" community in terms of 433 composition. What we suggest is that a community would be "recovered" when it has 434 similar performing conditions to the neighboring undisturbed community. The 435 performance of the community can be inferred by the soil nutrient content and 436 characteristics. Due to the significant differences in physicochemical parameters between microcosms and control sites at 12 months, we can conclude that despite the diversity found at the Churince soils, the small patches (1 kg mesh bags) did not recover to resemble undisturbed soil in either site, after a year of migration and succession. Nevertheless, it seems they followed a parallel paths for such recovery at the beginning 441 of the succession and diverged in later stages.

443 Conclusions

444 This is the first study on bacterial soil dynamics conducted at the CCB. Our results 445 provide important insight into microbial community dynamics in response to a 446 disturbance (secondary succession). In this study we found changes in community 447 composition across time that were indicative of the successional process. Our data 448 showed evidence of similar initial colonizers in both sites, but the divergence in later 449 successional stages reflects stochastic factors suggesting a species sorting and neutral 
450 effects. While community descriptions based only on 16S rRNA gene analysis do not 451 reflect the full metabolic plasticity of the communities, this study provides important 452 insight into microbial succession patterns. For further research metagenomics and 453 measures of the rates of the physiological traits are necessary to corroborate our results. 454 Notwithstanding, it is interesting that succession of small, perturbed spots is very slow; 455 this reveals the temporal scale is important for this community in terms of resilience, but 456 general long-term monitoring is necessary to better understand the temporal patterns 457 and natural variability of this area. Changes in microbial communities due to disturbance 458 may directly affect ecosystem processes, which are vital in a protected natural area, 459 threatened by over-exploitation of aquifers such as is occurring in the CCB.

461 Acknowledgements: We are grateful to Rodrigo González Chauvet, German Bonilla 462 Rosso and other members within the laboratory of Evolución Molecular y Experimental 463 for assistance with the sample collection; to Celeste Martínez-Piedragil, Rodrigo 464 Velázquez-Durán and Maribel Nava-Mendoza for assistance with soil chemical analysis; 465 to Laura Espinosa Asuar and Erika Aguirre Planter for help with molecular, sequencing 466 work and logistic support; to Ana Gutiérrez-Preciado and Jaime Gasca-Pineda for 467 bioinformatics assistance. We specially thank the APFF of Cuatro Cienegas for their 468 support and logistics.

470 References

471 Begon M, Townsend CR \& Harper JL (2006) Ecology: from individuals to ecosystems. 472 4th ed. Wiley-Blackwell.

473 Bremmer JM \& Mulvaney CS (1982) Total Nitrogen. Methods of Soil Analysis Agronomy 

Society of Agronomy, Madison.

476 Burke C, Steinberg P, Rusch D, Kjelleberg S \& Torsten T (2011) Bacterial community assembly based on functional genes rather than species. Proceedings of the National Academy of Sciences 108: 14288-14293.

479 Burke C, Thomas T, Lewis M, Steinberg P \& Kjelleberg S (2011) Composition, 480 uniqueness and variability of the epiphytic bacterial community of the green alga Ulva australis. ISME Journal 5: 590-600.

482

Caruso T, Chan Y, Lacap DC, Lau MCY, McKay CP \& Pointing SB (2011) Stochastic and deterministic processes interact in the assembly of desert microbial communities on a global scale. ISME Journal 5: 1406-1413.

Cleveland CC \& Liptzin D (2007) C:N:P stoichiometry in soil: is there a "Redfield ratio" for the microbial biomass? Biogeochemistry 85: 235-252.

Collins SL, Sinsabaugh RL, Crenshaw C, Green L, Porras-Alfaro A, Stursova M \& Zeglin LH (2008) Pulse dynamics and microbial processes in aridland ecosystems. Journal of Ecology 96: 413-420.

Daniel R (2005) The metagenomics of soil. Nature Reviews Microbiology 3: 470-478.

DeSantis T Z et al. (2006) Greengenes, a chimera-checked 16S rRNA gene database and workbench compatible with ARB. Applied and Environmental Microbiology 72: 5069-5072.

Dunbar J, Takala S, Barns S M, Davis J a \& Kuske C R (1999) Levels of bacterial community diversity in four arid soils compared by cultivation and 16S rRNA gene cloning. Applied and Environmental Microbiology 65: 1662-1669. 
497 Eichorst S a, Breznak J a \& Schmidt TM (2007) Isolation and characterization of soil 498 bacteria that define Terriglobus gen. nov., in the phylum Acidobacteria. Applied and Environmental Microbiology 73: 2708-2717.

500

501

502

\section{3}

504

505

506

507

508

509

510

511

512

513

514

515

516

Elser JJ, Schampel JH, Garcia-Pichel F, Wade BD, Souza V, Eguiarte L, Escalante A \& Farmer JD (2005) Effects of phosphorus enrichment and grazing snails on modern stromatolitic microbial communities. Freshwater Biology 50: 1808-1825.

Fierer N, Bradford M a \& Jackson RB (2007) Toward an ecological classification of soil bacteria. Ecology 88: 1354-1364.

Fierer N, Nemergut Diana, Knight R \& Craine JM (2010) Changes through time: integrating microorganisms into the study of succession. Research in Microbiology 161: 635-642.

Gundlapally SR \& Garcia-Pichel F (2006) The community and phylogenetic diversity of biological soil crusts in the Colorado Plateau studied by molecular fingerprinting and intensive cultivation. Microbial Ecology 52: 345-357.

Haas BJ et al. (2011) Chimeric 16S rRNA sequence formation and detection in Sanger and 454-pyrosequenced PCR amplicons. Genome research 21: 494-504.

Holben WE, Jansson JK, Chelm BK \& Tiedje JM (1988) DNA Probe Method for the Detection of Specific Microorganisms in the Soil Bacterial Community. Applied and Environental Microbiology 54: 703-711.

Huffman EWD (1977) Performance of a new automatic carbon dioxide coulometer. Microchemical Journal 22: 567-573.

Huse SM, Welch DM, Morrison HG \& Sogin ML (2010) Ironing out the wrinkles in the rare biosphere through improved OTU clustering. Environmental Microbiology 12: 
521 Janssen PH (2006) Identifying the dominant soil bacterial taxa in libraries of 16 S rRNA and 16S rRNA genes. Applied and Environmental Microbiology 72: 1719-1728.

523 Kuske C.R., Barns S.M. \& Busch JD (1997) Diverse uncultivated bacterial groups from 524 soils of the arid southwestern United States that are present in many geographic 525

Murphy J \& Riley JP (1962) A modified single solution method for the determination of

Lindström ES \& Langenheder S (2012) Local and regional factors influencing bacterial community assembly. Environmental Microbiology Reports 4: 1-9.

López-Lozano NE, Eguiarte LE, Bonilla-Rosso G, García-Oliva F, Martínez-Piedragil C, Rooks C \& Souza V (2012) Bacterial communities and the nitrogen cycle in the gypsum soils of cuatro ciénegas basin, coahuila: a Mars analogue. Astrobiology 12: $699-709$.

Montaño NM, García-Oliva F \& Jaramillo VJ (2007) Dissolved organic carbon affects soil microbial activity and nitrogen dynamics in a Mexican tropical deciduous forest. Plant and Soil 295: 265-277. phosphate in natural waters. Analytica Chimica Acta 27: 31-36.

Nagy ML, Pérez A \& Garcia-Pichel F (2005) The prokaryotic diversity of biological soil crusts in the Sonoran Desert (Organ Pipe Cactus National Monument, AZ). FEMS Microbiology Ecology 54: 233-245. 
543 Navarro JB, Moser DP, Flores A, Ross C, Rosen MR, Dong H, Zhang G \& Hedlund BP

544 (2009) Bacterial succession within an ephemeral hypereutrophic Mojave Desert 545 playa Lake. Microbial Ecology 57: 307-320.

546 Nemergut DR, Anderson SP, Cleveland CC, Martin AP, Miller AE, Seimon A \& Schmidt 547 SK (2007) Microbial community succession in an unvegetated, recently deglaciated

\section{9}

550

551

Ofiteru ID, Lunn M, Curtis Thomas P, Wells GF, Criddle CS, Francis C a \& Sloan WT (2010) Combined niche and neutral effects in a microbial wastewater treatment community. Proceedings of the National Academy of Sciences of the United States of America 107: 15345-15350.

Prosser $\mathrm{Jl}$ et al. (2007) The role of ecological theory in microbial ecology. Nature reviews. Microbiology 5: 384-392.

Pruesse, E., C. Quast, K. Knittel, B. Fuchs, W. Ludwig JPFOG (2007) SILVA: a comprehensive online resource for quality checked and aligned ribosomal RNA sequence data compatible with ARB. Nucleic Acids Research 35: 7188-7196.

Reynolds S (1970) The gravimetric method of soil moisture determination Part IA study of equipment, and methodological problems. Journal of Hydrology 11: 258-273.

Roesch LFW et al. (2007) Pyrosequencing enumerates and contrasts soil microbial diversity. ISME Journal 1: 283-290.

Schloss PD et al. (2009) Introducing mothur: open-source, platform-independent, community-supported software for describing and comparing microbial communities. Applied and Environmental Microbiology 75: 7537-7541.

565 Schloss PD (2010) The effects of alignment quality, distance calculation method, 
sequence filtering, and region on the analysis of 16S rRNA gene-based studies. PLoS Computational Biology 6: e1000844.

568 Schloss, PD \& Handelsman J (2006) Introducing SONS, a tool for OTU-based 569 comparisons of membership and structure between microbial communities. Applied and Environmental Microbiology 72: 6773-6779.

571 Schmidt S, Costello E \& Nemergut DR (2007) Biogeochemical consequences of rapid 572 microbial turnover and seasonal succession in soil. Ecology 88: 1379-1385.

573 Sun Y, Wolcott RD \& Dowd SE (2011) Tag-Encoded FLX Amplicon Pyrosequencing for 574 the Elucidation of Microbial and Functional Gene Diversity in Any Environment. 575 Methods in Molecular Biology 733: 129-141.

Vance E, Brookes P \& Jenkinson D (1987) An extraction method for measuring soil microbial biomass C. Soil Biology and Biochemistry 19: 703-707.

Wall DH \& Virginia RA (1999) Controls on soil biodiversity: insights from extreme environments. Applied Soil Ecology 13: 137-150.

Wang Q, Garrity GM, Tiedje JM \& Cole JR (2007) Naive Bayesian classifier for rapid 581 assignment of rRNA sequences into the new bacterial taxonomy. Applied and Environmental Microbiology 73: 5261-5267.

Woodcock S, van der Gast CJ, Bell T, Lunn M, Curtis Thomas P, Head IM \& Sloan WT (2007) Neutral assembly of bacterial communities. FEMS Microbiology Ecology 62: 171-180.

Youssef NH \& Elshahed MS (2009) Diversity rankings among bacterial lineages in soil. ISME Journal 3: 305-313. 


\section{Figure 1}

\section{sampling effect}

Rarefaction curves of the A) Dry Lagoon and B) River in all sampling dates (3, 6, 9 and 12 months). OTUs were determined at $97 \%$ sequence identity.
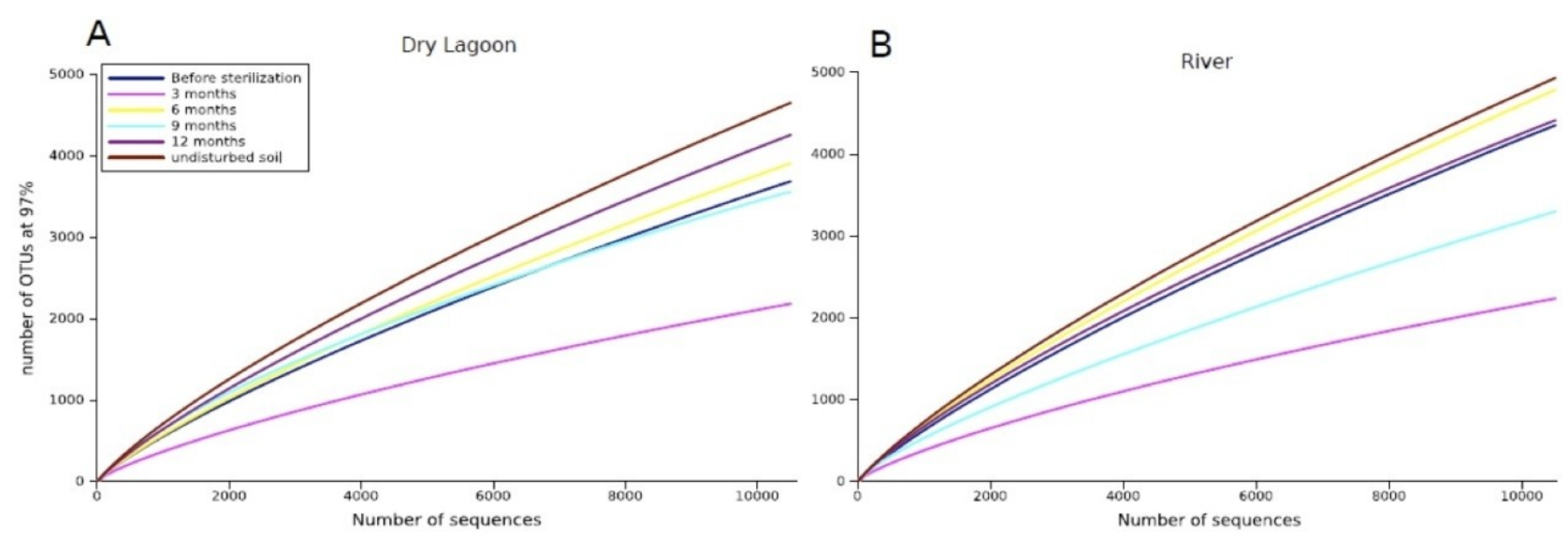

Figure 1. Rarefaction curves of the A) Dry Lagoon and B) River in all sampling dates (3, 6, 9 and 12 months). OTUs were determined at $97 \%$ sequence identity. 


\section{Figure 2}

relationship between diversity and environment

CCA ordination biplot of the most abundant family composition during the secondary succesional process. Vectors represent the soil characteristics, while centroids indicate different 454 pyrosequence 16S rRNA gene amplicon libraries across the time. Temporal replicates that are close together on the ordination diagram are more similar (in terms of their microbial community structure) than replicates that are farther apart.

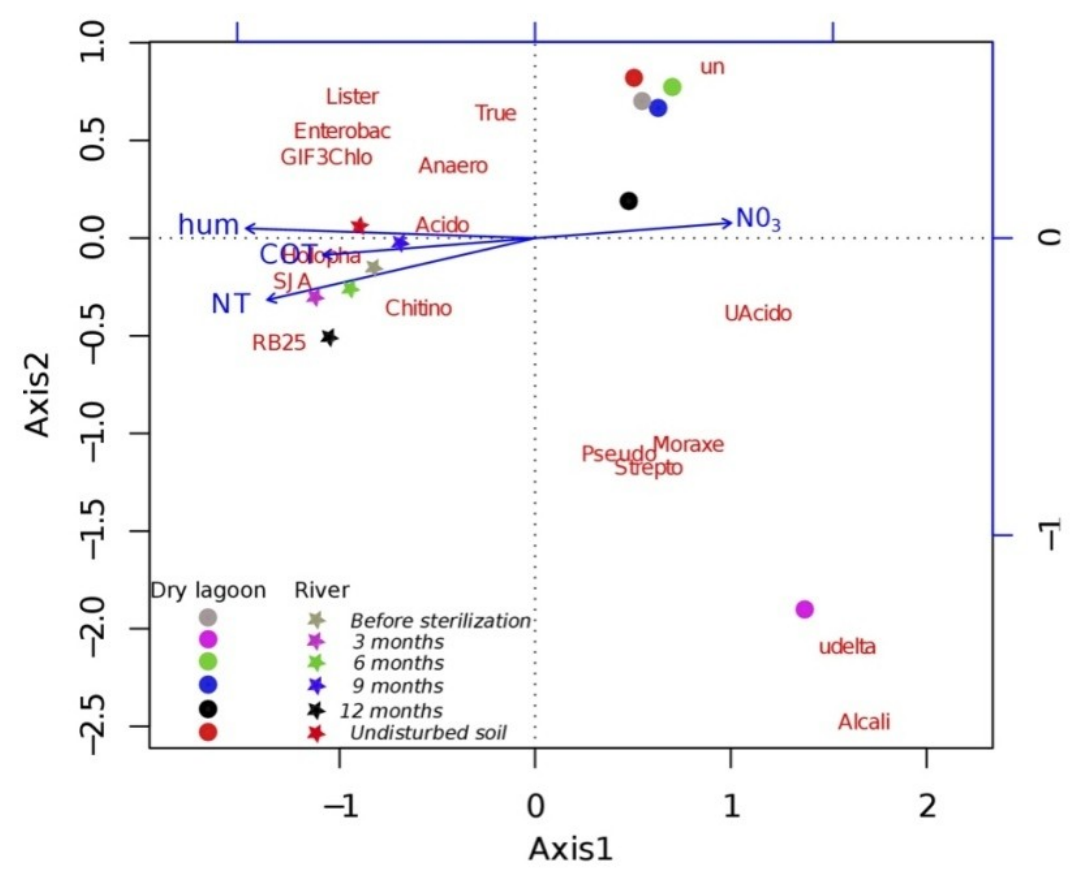

Figure 2. CCA ordination biplot of the most abundant family composition during the secondary succesional process. Vectors represent the soil characteristics, while centroids indicate different 454 pyrosequence $16 \mathrm{~S}$ rRNA gene amplicon libraries across the time. Temporal replicates that are close together on the ordination diagram are more similar (in terms of their microbial community structure) than replicates that are farther apart. 


\section{Figure 3}

relationship between samples

Figure 3. Clustering of the $16 \mathrm{~S}$ rRNA community composition at $97 \%$ similarity based on the Bray-Curtis algorithm of ecotype abundance. The cluster diagram of sample similarity generated using the Jaccard Index showed the same pattern (data not shown).

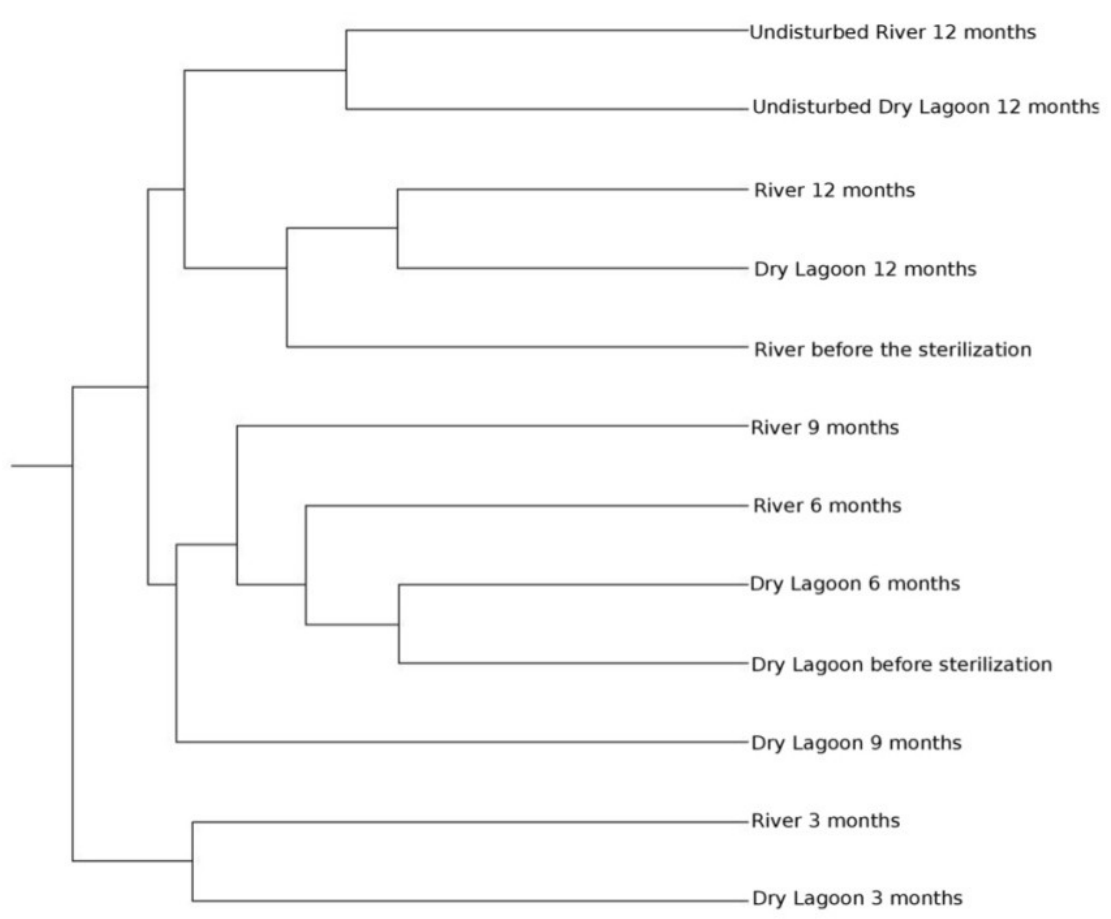

Figure 3. Clustering of the $16 \mathrm{~S}$ rRNA community composition at $97 \%$ similarity based on the Bray-Curtis algorithm of ecotype abundance. A 


\section{Table $\mathbf{1}_{\text {(on next page) }}$}

Soil and nutrients

Soil biogeochemical parameters in each sampling date for both sites. Statistical analysis was done as a

2 way ANOVA. Numbers represent the mean \pm SD with $\mathrm{F}$ values and significance levels: $*=\mathrm{P}<0.05$, $* *=\mathrm{P}<0.01, * * *=\mathrm{P}<0.0001$, ns $=$ not significant. 
Table 1 . Soil biogeochemical parameters in each sampling date for both sites Dry Lagoon and River. Analysis was done as a 2 way ANOVA, the mean \pm SD with $\mathrm{F}$ values and significance levels: $*=\mathrm{P}<0.05$, $* *=\mathrm{P}<0.01$, $* * *=\mathrm{P}<0.0001$, ns $=$ not significant.

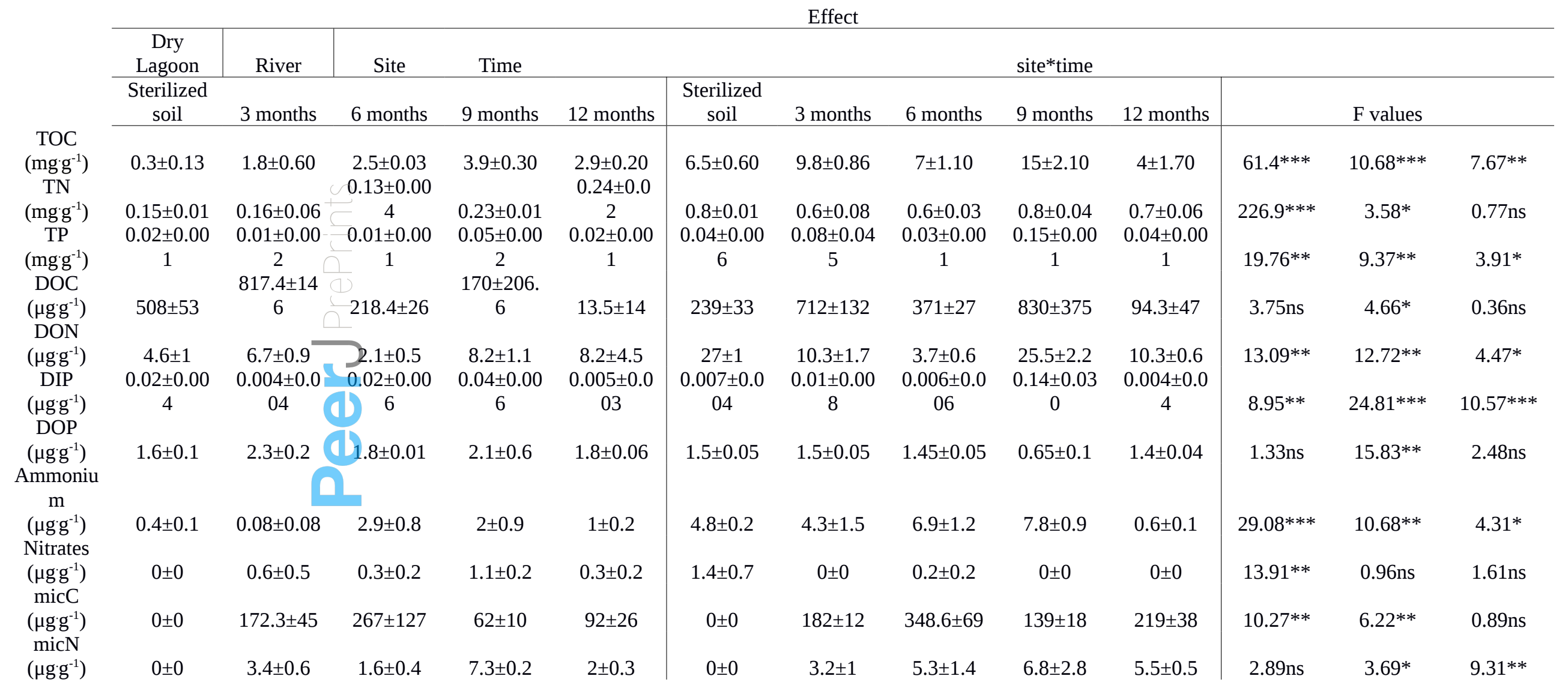




\section{Table $2_{\text {(on next page) }}$}

Changes in biogeochemical parameters

Mean \pm SD of biogeochemical parameters of microcosms and undisturbed soil samples of each site for the last sampling date, 12 months ( $\mathrm{n}=3$ ). A two way ANOVA was used for statistical comparison and results are presented as $\mathrm{F}$ values with significance levels: $*=\mathrm{P}<0.05, * *=\mathrm{P}<0.01, * * *=\mathrm{P}<$ $0.0001, \mathrm{~ns}=$ not significant. 
Table 2. Biogeochemical parameters of microcosms and undisturbed soil samples of each site for the last sampli months ( $\mathrm{n}=3$ ). Mean \pm SD with F values and significance levels: $*=\mathrm{P}<0.05$, $* *=\mathrm{P}<0.01$, $* * *=\mathrm{P}<0.0001$, $\mathrm{r}$ significant a.

Effect

$\begin{array}{ccccccc} & & & & \text { Treatment } & \text { Site } \\ & \begin{array}{c}\text { Dry Lagoon } \\ \text { undisturbed }\end{array} & \begin{array}{c}\text { Dry Lagoon } \\ \text { microcosms }\end{array} & \begin{array}{c}\text { River } \\ \text { undisturbed }\end{array} & \begin{array}{c}\text { River } \\ \text { microcosms }\end{array} & \text { F values } \\ \text { TOC }\left(\mathrm{mg}^{-1}\right) & 2.9 \pm 0.3 & 2.9 \pm 0.2 & 23.2 \pm 3.9 & 4 \pm 1.7 & 19.7^{* *} & 24.8^{* *} \\ \text { TN }\left(\mathrm{mg} \cdot \mathrm{g}^{-1}\right) & 0.2 \pm 0.005 & 0.24 \pm 0.015 & 1.1 \pm 0.2 & 0.7 \pm 0.06 & 5.02^{\mathrm{ns}} & 54.7^{* * *} \\ \text { TP }\left(\mathrm{mg} \cdot \mathrm{g}^{-1}\right) & 0.023 \pm 0.001 & 0.024 \pm 0.001 & 0.06 \pm 0.008 & 0.04 \pm 0.006 & 2.3^{\mathrm{ns}} & 26.9^{* * *} \\ \text { DOC }\left(\mu \mathrm{g}^{-1}\right) & 13.5 \pm 9.4 & 94.3 \pm 35.4 & 20.4 \pm 9.4 & 110 \pm 12.3 & 0.2^{\mathrm{ns}} & 38.8^{* * *} \\ \text { DON }\left(\mu \mathrm{gg}^{-1}\right) & 1.4 \pm 0.5 & 8.2 \pm 4.5 & 0.5 \pm 0.12 & 9.5 \pm 0.6 & 24.2^{* * *} & 0.15^{\mathrm{ns}} \\ \text { DIP }\left(\mu g \cdot \mathrm{g}^{-1}\right) & 0.0 \pm 0 & 0.005 \pm 0.003 & 0.0 \pm 0 & 0.004 \pm 0.004 & 3.7^{\mathrm{ns}} & 0.36^{\mathrm{ns}} \\ \text { DOP }\left(\mu \mathrm{gg}^{-1}\right) & 1.5 \pm 0.04 & 1.8 \pm 0.06 & 1.1 \pm 0.05 & 1.43 \pm 0.04 & 45.5^{* * *} & 77.82^{* * *} \\ \text { Ammonium }\left(\mu \mathrm{g} \cdot \mathrm{g}^{-1}\right) & 0.95 \pm 0.2 & 1.3 \pm 0.1 & 0.6 \pm 0.1 & 1.45 \pm 0.1 & 13.4^{* *} & 0.26^{\mathrm{ns}} \\ \text { Nitrates }\left(\mu \mathrm{g}^{-1}\right) & 0.8 \pm 0.4 & 0.34 \pm 0.2 & 0.0 \pm 0 & 0.0 \pm 0 & 0.86^{\mathrm{ns}} & 5.4^{*} \\ \text { MicC }\left(\mu \mathrm{g} \cdot \mathrm{g}^{-1}\right) & 43.5 \pm 20 & 92.1 \pm 25.7 & 206 \pm 17 & 219 \pm 38 & 1.4^{\mathrm{ns}} & 32^{* * *} \\ \text { MicN }\left(\mu \mathrm{g} \cdot \mathrm{g}^{-1}\right) & 4.9 \pm 0.7 & 2.1 \pm 0.3 & 11.2 \pm 2.6 & 5.5 \pm 0.5 & 9.1^{*} & 12.3^{* *}\end{array}$




\section{Table 3 (on next page)}

Microbial diversity

Relative abundance of bacterial phyla for each sample. Values represent the percentage of each group in the respective library. 
Table 3. Distribution of bacterial phyla. The relative abundance of bacterial phyla in each of the sampling dates and site. Values represent the percentage of each group in the respective library.

\section{Dry lagoon}

\begin{tabular}{|c|c|c|c|c|c|c|c|c|c|}
\hline & $\begin{array}{c}\text { Before } \\
\text { sterilization }\end{array}$ & 3 months & 6 months & 9 months & 12 months & $\begin{array}{l}\text { Undisturbed } \\
\text { soil }\end{array}$ & $\begin{array}{c}\text { Before } \\
\text { sterilization }\end{array}$ & 3 months & $6 \mathrm{~m}$ \\
\hline Acidobacteria & 44.41 & 30.56 & 42.02 & 24.26 & 42.68 & 33.36 & 59.60 & 49.32 & \\
\hline Bacteroidetes & 4.68 & 0.24 & 2.40 & 7.40 & 7.34 & 3.16 & 9.03 & 0.00 & \\
\hline Chloroflexi & 0.98 & 0.01 & 1.25 & 4.61 & 0.97 & 9.36 & 2.05 & 8.37 & \\
\hline Gemmatimonadetes & 0.70 & 0.02 & 1.71 & 0.82 & 1.48 & 0.48 & 1.92 & 0.02 & \\
\hline Deferribacteres & 0.00 & 0.00 & 0.00 & 0.00 & 0.00 & 0.02 & 0.90 & 1.08 & \\
\hline TM6 & 0.46 & 0.00 & 0.13 & 4.53 & 0.51 & 0.80 & 0.89 & 0.02 & \\
\hline Firmicutes & 0.31 & 10.73 & 0.59 & 2.04 & 0.37 & 2.44 & 0.82 & 21.69 & \\
\hline Actinobacteria & 0.63 & 4.69 & 1.00 & 0.74 & 0.43 & 1.74 & 0.60 & 0.19 & \\
\hline Deinococcus-Thermus & 2.80 & 0.33 & 6.09 & 2.26 & 0.69 & 1.21 & 0.45 & 0.00 & \\
\hline Cyanobacteria & 0.20 & 0.31 & 0.20 & 0.06 & 0.21 & 0.46 & 0.39 & 0.16 & \\
\hline Verrucomicrobia & 0.08 & 0.00 & 0.22 & 2.38 & 1.24 & 0.72 & 0.31 & 0.00 & \\
\hline Chlamydiae & 1.01 & 0.01 & 0.38 & 0.29 & 0.85 & 1.62 & 0.54 & 0.00 & \\
\hline Planctomycetes & 0.51 & 0.00 & 0.20 & 0.08 & 0.01 & 0.03 & 0.12 & 4.62 & \\
\hline TM7 & 0.23 & 0.00 & 0.05 & 3.65 & 0.42 & 0.22 & 0.39 & 0.00 & \\
\hline TA06 & 0.00 & 0.00 & 0.00 & 0.00 & 0.00 & 0.00 & 0.00 & 2.97 & \\
\hline OP11 & 0.00 & 0.00 & 0.00 & 0.00 & 0.00 & 0.00 & 0.02 & 0.00 & \\
\hline unclassified & 33.59 & 12.01 & 33.56 & 26.63 & 18.21 & 30.55 & 0.00 & 0.00 & \\
\hline \multicolumn{10}{|l|}{ Proteobacteria } \\
\hline Alphaproteobacteria & 1.88 & 0.16 & 1.14 & 3.52 & 4.32 & 2.47 & 7.23 & 0.15 & \\
\hline Betaproteobacteria & 0.04 & 6.56 & 0.03 & 0.41 & 0.40 & 0.03 & 1.35 & 0.01 & \\
\hline Deltaproteobacteria & 0.54 & 8.95 & 0.30 & 1.04 & 0.59 & 3.64 & 4.31 & 0.85 & \\
\hline Gammaproteobacteria & 5.84 & 24.95 & 7.32 & 12.27 & 17.47 & 3.86 & 21.40 & 10.52 & \\
\hline Other groups $(<1 \%)$ & 1.10 & 0.47 & 1.41 & 3.02 & 1.80 & 3.86 & 1.70 & 0.04 & \\
\hline
\end{tabular}




\section{Table 4(on next page)}

Relationship between soil and diversity

Spearman's rank correlations between the relative abundances of the most abundant bacterial phyla,

proteobacterial classes and bacterial families, and the soil properties in CCB. Bold numbers: $\mathrm{P}<0.05$;

Bold and underlined numbers $\mathrm{P}<0.001$. 
Table 4: Bacterial 16S rRNA amplicon diversity analysis of two arid soil sites in Cuatro Cienegas, Coahuila, Mexico.

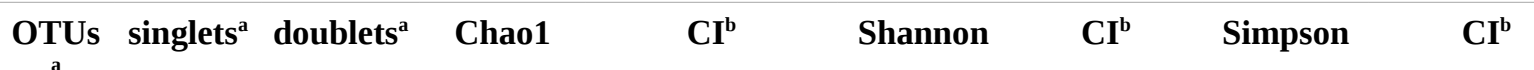

\section{Dry lagoon}

$\begin{array}{lccccccccc}\text { Before sterilization } & 6586 & 4917 & 882 & 43226 & (39437-47450) & 7.31 & (7.27-7.34) & 0.007 & (0.006-0.007) \\ 3 \text { months } & 4106 & 2760 & 587 & 20166 & (18253-22337) & 6.07 & (6.03-6.11) & 0.020 & (0.019-0.021) \\ 6 \text { months } & 7518 & 5830 & 1093 & 42815 & (39583-46372) & 7.59 & (7.56-7.63) & 0.004 & (0.004-0.004) \\ 9 \text { months } & 3552 & 2433 & 451 & 10097 & (9334-10961) & 7.17 & (7.15-7.21) & 0.002 & (0.002-0.003) \\ \text { 12 months } & 6882 & 5114 & 808 & 60661 & (54582-67515) & 7.70 & (7.66-7.73) & 0.004 & (0.004-0.005) \\ \text { Undisturbed soil } & 8258 & 7157 & 1135 & 53773 & (49545-58434) & 8.16 & (8.13-8.19) & 0.001 & (0.001-0.001) \\ \text { River } & & & & & & & & & \\ \text { Before sterilization } & 8268 & 6797 & 1085 & 53676 & (49534-58233) & 7.80 & (7.76-7.83) & 0.005 & (0.004-0.005) \\ \text { 3 months } & 3785 & 2878 & 657 & 17395 & (15706-19323) & 6.04 & (6.00-6.08) & 0.013 & (0.013-0.014) \\ 6 \text { months } & 9001 & 7289 & 1148 & 61455 & (56784-66583) & 8.24 & (8.21-8.26) & 0.001 & (0.001-0.002) \\ \text { 9 months } & 6530 & 6607 & 1202 & 33236 & (30685-36056) & 7.35 & (7.32-7.38) & 0.003 & (0.003-0.003) \\ \text { 12 months } & 6356 & 4728 & 734 & 27928 & (25926-30135) & 7.80 & (7.75-7.82) & 0.002 & (0.002-0.002) \\ \text { Undisturbed soil } & 8461 & 7019 & 1171 & 52934 & (48931-57332) & 8.23 & (8.20-8.25) & 0.001 & 0.001-0.001)\end{array}$

All samples were normalized to 10, 441 sequences (table S3) for diversity comparison, values in parentheses represent the lower and upper 95\% confidence interval associated with the Chao1 nonparametric estimator. a. values calculated based on $97 \%$ threshold

b. Lower and upper $95 \%$ confident intervals associated with the diversity parameter.

c. Good's coverage estimator 


\section{Table 5 (on next page)}

16S diversity

Bacterial 16S rRNA amplicon diversity analysis of two arid soil sites in Cuatro Cienegas, Coahuila, Mexico. 
Table 5. Spearman's rank correlations between the relative abundances of the most abundant bacterial phyla, proteobacterial classes and bacterial families, and the soil properties in CCB. Bold numbers: $\mathrm{P}<0.05$; Bold and underlined numbers $\mathrm{P}<0.001$.

\begin{tabular}{|c|c|c|c|c|}
\hline $\begin{array}{l}\text { Taxonomic Group } \\
\text { Phyla }\end{array}$ & Humidity & $\begin{array}{l}\text { Total } \\
\text { Organic } \\
\text { Carbon }\end{array}$ & $\begin{array}{c}\text { Total } \\
\text { Nitrogen }\end{array}$ & Nitrate \\
\hline Acidobacteria & 0.54 & 0.59 & 0.57 & -0.66 \\
\hline Bacteroidetes & 0.46 & 0.46 & 0.51 & -0.16 \\
\hline Chloroflexi & 0.71 & 0.65 & 0.51 & -0.24 \\
\hline Firmicutes & 0.24 & 0.27 & 0.26 & -0.01 \\
\hline Deinococcus-Thermus & 0.02 & -0.13 & -0.23 & 0.05 \\
\hline Gemmatimonadetes & 0.50 & 0.43 & 0.51 & -0.27 \\
\hline Actinobacteria & -0.07 & -0.30 & -0.16 & 0.42 \\
\hline TM6 & 0.58 & 0.59 & 0.49 & 0.03 \\
\hline Cyanobacteria & 0.50 & 0.32 & 0.50 & -0.12 \\
\hline
\end{tabular}

\section{Class}

$\begin{array}{rcccc}\text { Alphaproteobacteria } & 0.49 & 0.47 & \mathbf{0 . 6 4} & -0.10 \\ \text { Betaproteobacteria } & -0.06 & -0.02 & 0.24 & 0.22 \\ \text { Deltaproteobacteria } & 0.44 & 0.37 & 0.53 & -0.01 \\ \text { Gammaproteobacteria } & -0.12 & -0.02 & 0.22 & 0.07\end{array}$

Family

$\begin{array}{rcccc}\text { Acidobacteriaceae } & \mathbf{0 . 6 9} & \mathbf{0 . 6 2} & \mathbf{0 . 6 3} & \mathbf{- 0 . 6 0} \\ \text { Holophagaceae } & \mathbf{0 . 7 5} & \underline{\mathbf{0 . 8 4}} & \mathbf{0 . 7 8} & \mathbf{- 0 . 5 7} \\ \text { RB25 (Holophagae) } & \mathbf{0 . 7 1} & \mathbf{0 . 6 8} & \mathbf{0 . 7 1} & \mathbf{- 0 . 6 5} \\ \text { SJA-36 (Holophagae) } & \mathbf{0 . 6 7} & \mathbf{0 . 7 4} & \mathbf{0 . 7 1} & -0.70 \\ \text { Unclassified Acidobacteria } & \underline{\mathbf{- 0 . 9 3}} & \underline{\mathbf{- 0 . 8 9}} & \underline{\mathbf{- 0 . 8 2}} & \mathbf{0 . 6 0} \\ \text { Moraxellaceae } & -0.12 & -0.22 & -0.29 & -0.05 \\ \text { Chitinophagaceae } & 0.42 & 0.41 & 0.53 & -0.04 \\ \text { Truepera } & -0.11 & -0.24 & -0.30 & 0.07 \\ \text { Anaerolineaceae } & 0.63 & 0.47 & 0.44 & 0.09 \\ \text { Pseudomonadaceae } & -0.45 & -0.24 & -0.10 & 0.18 \\ \text { Streptococcaceae } & -0.50 & -0.43 & -0.53 & 0.24 \\ \text { Enterobacteriaceae } & \mathbf{0 . 5 6} & 0.51 & 0.39 & \underline{\mathbf{- 0 . 8 4}} \\ \text { GIF3 (Chloroflexi) } & \mathbf{0 . 7 6} & \mathbf{0 . 7 9} & \mathbf{0 . 7 6} & \mathbf{- 0 . 7 3}\end{array}$




$\begin{array}{rcccc}\text { Alcaligenaceae } & -0.37 & -0.24 & -0.03 & 0.50 \\ \text { unclassified } & \mathbf{- 0 . 8 0} & \underline{\mathbf{- 0 . 8 5}} & \underline{\mathbf{- 0 . 8 2}} & \mathbf{0 . 6 6} \\ \text { Deltaproteobacteria } & & & & \\ \text { Listeriaceae } & 0.15 & 0.20 & 0.18 & -0.46\end{array}$

